\title{
Motivated Strategies for Learning and Cognitive Styles Among a Sample of UAE High School Students
}

\author{
Abdalla El-Mneizel \\ University of Sharjah, Sharjah, United Arab Emirates
}

\author{
Adnan Atoum \\ Yarmouk University, Irbid, Jordan
}

\begin{abstract}
The present study aimed at exploring the motivated learning strategies and cognitive styles among a sample of United Arab Emirates (UAE) high school students. To achieve the objectives of the study, a sample consisted of 800 male and female students was chosen and the Motivated Learning Strategies Scale and the Cognitive Styles Scale were validated and administered to the students. Results of the study showed that the task values motivated learning strategy ranked first followed by test anxiety, self-efficacy, and self-regulation strategies in order. Statistically significant differences in scores of test anxiety and self-regulation motivated learning strategies based on gender were found and in favor of female students. Also, statistical differences in all motivated learning strategies were found based on various academic stream and in favor of scientific stream. No statistically significant differences in motivated learning strategies were found based on various school grades. Results also showed that students have a tendency to be field-independent. Statistical differences in field-independent cognitive style were found in favor of male students, science stream, and 10th grade students. Also, statistical differences in field-dependent cognitive style were found in favor of female students, arts stream, and 11th grade students.
\end{abstract}

Keywords: motivated strategies for learning, cognitive styles, Jordanian students

\section{Introduction}

Students' academic achievement is affected by many cognitive factors, such as cognitive abilities, and affective factors, such as motivation and learning strategies and styles. Good achievers are usually described as highly motivated and hard working rather than they are simply intelligent.

Students' motivated strategies for learning have been considered as the milestone of the method that learners used to organize their efforts and activities in different academic situations. Motivated strategies for learning contribute to make learning easy and make the task by learner enjoyable and interesting. Higher level of motivated learners are capable of organizing and managing their learning goals efficiently, and they often use cognitive and meta-cognitive strategies frequently to improve their learning tasks.

Pajares (2001) examined this concept in terms of cognitive beliefs and emotional aspects that control the learning processes. However, researchers did not agree on the components of this concept. Usava and Gibson (1986) focused on issues of learners' attention, the desire to learn, and ability to keep learning in a continuous state. Johnson (1991) focused on internal/external goal orientation, the value of the goal, beliefs of control over learning, and self-efficacy. While Pearson and Cary (1995) focused on perceived self-efficacy, 
self-effectiveness, and meta-cognitions.

Fang (2014) showed that most relevant literature has reported that students' motivated strategies for learning is statistically significant in correlation to students' academic achievement on many subject matters and disciplines. So, Fang investigated whether there is a statistically significant correlation between students' motivated strategies for learning and students' academic achievement. The results showed a statistical correlation between motivated strategies for learning scores and performance.

Matos, Lens, and Vansteenkiste (2007) examined the relationship between students' achievement goals, their use of learning strategies, and their academic achievement. Results showed that achievement goals predicted using learning strategies but not academic achievement.

Also, a study by Ahmad (2005) examined the relationship between motivated learning strategies, learning environment, and intelligence among 300 high school students. Results showed a positive significant correlation between motivated learning strategies, learning environment, and intelligence.

Motivated strategies for learning are interconnected to another factor, which is cognitive styles. Cognitive styles reflect the methods that the learner processes new information and blends it within the cognitive structure, and the ability to retrieve it later. Generally, students are more successful when they are given the opportunity to study through their own cognitive style (Furner, Yahya, \& Duffy, 2005; Hatcher, 2000).

Several classifications of cognitive styles are known. Among that is R. Dunn and K. Dunn's classification that includes interpersonal, emotional, social, physiological, and psychological components (Cassidy, 2004; Lawrence, 1987). Other classifications of cognitive styles focused on sensory perception by determining whether learners prefer auditory, visual, touch, or motor methods (Abiator, 2001).

Field-dependent/independent is another way of classifying cognitive styles. Cassidy (2004) showed that some students prefer to do learning tasks individually (field-dependent) while others prefer to do learning tasks within a group practicing discussion and dialogue (field-independent). Originally, Witkin, Moore, Goodenough, and Cox (1977) stated that field-independent learners tend to rely on information provided by the outer world and are based on this overall field, while field-dependent as the tendency to be dependent on the total field so that the parts embedded within the field and are not easily perceived. For example, field-independent learners tend to rely less on the teacher or other learners in the classroom while field-dependent learners rely more on the teacher or classmates and value the relationships with others during learning.

Daniels (1996) summarized the general characteristics of field-dependent/independent learners. Field-dependents rely more on the surrounding perceptual field and show difficulty dealing with non-salient cues and ambiguous information, connecting new information to prior knowledge, and retrieving information from long-term memory. While field-independents perceive objects as separate from the field, distinguish between relevant and non-relevant items within the field, build structure to new information, and are better in retrieving information from memory.

R. Dunn, K. Dunn, and Price (1987) tested the relationship between cognitive styles and academic achievement among basic school students. Results showed that $46 \%$ of low achievers had no style preference, while $47 \%$ of higher achievers prefer auditory cognitive styles.

Also, a study was conducted by Woolhouse and Blaire (2003) to explore cognitive styles of low and high achievers. Results showed a semi-normal distribution of students on different cognitive styles. In specific, 37\% of high achievers had a theoretical cognitive style, while $38 \%$ of the low achievers had an impulsive cognitive style. 
In United Arab Emirates (UAE), Paul, Bojanczyk, and Lanphear (1994) explored the preferred cognitive styles of UAE university students. Results showed that students prefer styles that deal with issues of physical or applied nature rather than abstract nature.

As to research on cognitive styles and its relation to motivation and achievement, Shih and Gamon (2001) tested the relationships between student achievement, motivation, and cognitive styles among 99 students taking two Web-based courses. Results showed that two-thirds of the students were field-independent learners. Also, there were no significant differences in achievement between field-dependent and field-independent students. Also, students with different learning styles and backgrounds learned equally well in Web-based courses. Furthermore, motivation was the only significant factor that explained more than one-fourth of student achievement measured by class grade.

A study by Bolocofsky (2014) explored the relationship between field-dependent/independent and motivation. Tenth grade students were classified according to field-dependent scores and a motivational task. Results showed that field-dependent students increased their performance significantly when competing, while field-independent students showed a small and non-significant change.

Previous studies showed the importance of motivated learning strategies and cognitive styles in learning and students' achievement and their relations to so many other variables. Students who use motivated learning strategies showed better performance than those who did not. Also, when teachers recognize student cognitive styles, they were better in dealing with students and students showed better achievement.

\section{Statement of the Problem}

Previous research had shown that motivated learning strategies and cognitive styles play a major role in effective learning and students' achievement. Therefore, the present study aimed at exploring motivated learning strategies and cognitive styles among a sample of UAE high school students. The present study attempted to answer the following four research questions:

1. What are the motivated learning strategies used by UAE high school students?

2. Are there statistical differences in motivated learning strategies due to variation in student's gender, academic stream, and school grades?

3. What are the cognitive styles used by UAE high school students?

4. Are there statistical differences in cognitive styles due to variation in student's gender, academic stream, and school grades?

\section{Significance of the Study}

The theoretical importance of the study stems from lack of research findings on motivated learning strategies and cognitive styles among UAE high school students.

Empirically, the results of the present study could be of importance in designing programs and school curriculum needed for high school students in UAE. It also can help guide students into improving their beliefs toward success or failure and exchange negative attitudes with positive ones toward learning.

\section{Definition of Terms}

Motivated learning strategies. Motivated learning strategies are behaviors and methods that reflect students' capabilities of monitoring their processes during learning. Operationally, it is reflect by the total score on the Motivated Learning Strategies Scale. 
Cognitive styles. Cognitive styles reflect the style of learning preferred by the learner during a task or a mission. Operationally, it is reflected by the total scores on the field-dependent/independent Cognitive Styles Scale.

\section{Methodology}

\section{Sample of the Study}

The sample of the study consisted of 800 male and female 10th-12th grade students from UAE governmental schools. Two schools were purposely chosen based on location and demographical variables from each state in the UAE. Table 1 shows the distribution of sample based on demographical variables.

Table 1

Distribution of Sample Based on Gender, Grade, and Stream

\begin{tabular}{|c|c|c|c|}
\hline & & $N$ & Total \\
\hline \multirow{2}{*}{ Gender } & Male & 325 & \multirow{2}{*}{800} \\
\hline & Female & 475 & \\
\hline \multirow{3}{*}{ Grade } & 10th & $130($ Male $=50 ;$ Female $=80)$ & \multirow{3}{*}{800} \\
\hline & 11 th & $303($ Male $=105 ;$ Female $=198)$ & \\
\hline & 12 th & $367($ Male $=170 ;$ Female $=197)$ & \\
\hline \multirow{2}{*}{ Stream } & Science & 468 & \multirow{2}{*}{800} \\
\hline & Arts & 302 & \\
\hline
\end{tabular}

\section{Instruments}

The Motivated Learning Strategies Scale. The scale was develop by Rao and Sachs (1999) and translated to Arabic language by Ahmad (2005). The scale consisted of 36 items divided equally into four domains, which are self-efficacy, task values, test anxiety, and self-regulation.

Ahmad (2005) presented good evidence of validity and reliability in addition to the original scales indicators. Validity was conducted through content validity and the criterion validity by calculating the correlation between the test scores with scores of the Need for Cognition Scale. Correlations for the domains were $0.74,0.71,0.76$, and 0.68 in order. Reliability was conducted through test-retest method and correlations for the domains were $0.74,0.82,0.67$, and 0.79 in order.

For the purpose of the present study, researchers conducted content validity by presenting the scale to 10 faculty members at Sharjah University faculty members for evaluation. Based on their remarks, minor changes were made to the language of the scale. Also, two methods of reliability were established. Cronbach's alpha values as indicators of internal consistency for the four domains were $0.74,0.70,0.57$, and 0.76 in order, and stability coefficient correlations were $0.74,0.82,0.67$, and 0.79 in order. The previous validity and reliability values were good indicators of the readiness of the scale to be used in the present study.

A 5-point Likert type responses that ranged from "Strongly agree" to "Strongly disagree" (with values of 5, 4, 3, 2, and 1) were used. The values for the negative items were reversed. The total scores for the whole scale ranged from 36-180 and for each domain ranged from 9-45.

To evaluate the results of the first question, the study employed the following norm to judge the degree of employing such strategies. Means assigned high scores to means between 3.67 and 5, average to means between 2.34 and 3.66, and low to means between 1 and 2.33 . 
The Cognitive Styles Scale. The scale was developed by Abu-Moghli, Khalaf, Halabi, and Wardam (2005) in Arabic language. The scale consisted of 24 items divided into two domains, field-independent (15 items) and field-dependent (nine items).

The original scale established content validity and internal consistency reliability through Cronbach's alpha value (0.89). For the purpose of the present study, the researchers conducted content validity by presenting the scale to 10 faculty members at Sharjah University faculty members for evaluation. Based on their remarks, minor changes were made to the language of the scale. Also, Cronbach's alpha values as indicators of internal consistency for the filed-independent domain was 0.83 and file-dependent domain was 0.60. The previous validity and reliability values were good indicators of the readiness of the scale to be used in the present study.

A 5-point Likert type responses that ranged from "Strongly agree" to "Strongly disagree" (with values of 5, $4,3,2$, and 1) were used. The values for the negative items were reversed. The total scores for the filed-independent domain ranged from 15-75 and for the field-dependent domain ranged from 9-45.

\section{Procedures}

After the sample was determined, the researchers visited the target schools and chose the classes with the school administrations. Both questionnaires were administered to students after explaining the objectives of the study and the researchers' assurances of the secrecy of the information they were about to submit.

\section{Design Methodology}

The study employed a survey descriptive type of methodology that includes the following variables:

(a) Independent variables: gender (male and female), academic stream (science and arts), and grade (10th, 11th, and 12th);

(b) Dependent variables: scores on the Cognitive Styles Scale and the Motivated Learning Strategies Scale.

\section{Results and Discussion}

To answer the first research question "What are the motivated learning strategies used by UAE high school students?", means, standard deviations, and rank for the motivated learning strategies scores were calculated, as shown in Table 2.

Table 2

Means, Standard Deviations, Level, and Rank for the Motivated Learning Strategies Domains Scores

\begin{tabular}{lllll}
\hline Motivated strategy & Mean & $S D$ & Level & Rank \\
\hline Self-efficacy & 3.05 & 0.83 & Average & 3 \\
Task values & 3.36 & 0.78 & Average & 1 \\
Test anxiety & 3.19 & 0.62 & Average & 2 \\
Self-regulation & 2.80 & 0.78 & Average & 4 \\
\hline
\end{tabular}

Results of Table 2 showed that all means for the four domains ranked as average scores of motivated learning strategies. The task values domain ranked first followed by test anxiety, self-efficacy, and self-regulation in order. It must be mentioned that test anxiety mean is a negative score and it reflects a state of motivated anxiety, but it remains around the average and it is close to the medium score. 
The previous results indicated average scores of motivated learning strategies among UAE students, which reflected a need for further improvements in employing more serious motivated strategies in classes and during interactions between students and their teachers. This also will help make learning easy and make the task by learner enjoyable and interesting which will affect students' achievement and learning outcomes as indicated by Gibson (1986) and Hatcher (2000) .

Also, it must be noted that the best motivated learning strategy was the task value with a mean of 3.36 $(67.2 \%)$. This reflects the UAE focus on values of the nature of the learning materials, persistence to performing, and attention to learning process. Also, more attention should be given to the self-regulation strategy which had the lowest mean of $2.80(56 \%)$. The self-regulation strategy is usually associated with higher level of thinking, such as meta-cognitive thinking which requires specific training.

To answer the second question "Are there statistical differences in motivated learning strategies due to variation in student's gender, academic stream, and grades?", means, standard deviations, and $t$-values for the motivated learning strategies domains based on gender were calculated, as shown in Table 3 .

Table 3

Means, Standard Deviations, and T-Values for the Motivated Learning Strategies Domains Based on Gender

\begin{tabular}{|c|c|c|c|c|c|c|}
\hline Domain & Gender & Freq. & Mean & $S D$ & $t$ & $p$ \\
\hline \multirow{2}{*}{ Self-efficacy } & Male & 324 & 2.99 & 0.78 & \multirow{2}{*}{1.69} & \multirow{2}{*}{0.09} \\
\hline & Female & 471 & 3.09 & 0.88 & & \\
\hline \multirow{2}{*}{ Task values } & Male & 324 & 3.38 & 0.84 & \multirow{2}{*}{0.60} & \multirow{2}{*}{0.55} \\
\hline & Female & 471 & 3.34 & 0.71 & & \\
\hline \multirow{2}{*}{ Test anxiety } & Male & 324 & 3.27 & 0.59 & \multirow{2}{*}{3.65} & \multirow{2}{*}{0.001} \\
\hline & Female & 473 & 3.11 & 0.64 & & \\
\hline \multirow{2}{*}{ Self-regulation } & Male & 324 & 2.73 & 0.75 & \multirow{2}{*}{2.27} & \multirow{2}{*}{0.024} \\
\hline & Female & 473 & 2.86 & 0.80 & & \\
\hline
\end{tabular}

Results in Table 3 showed significant statistical differences $(t=3.65 ; p=0.001)$ between males and females in scores of the test anxiety domain in favor of females (domain has negative values). Also, a statistically significant difference $(t=2.27 ; p=0.024)$ was found for the self-regulation domain in favor of females also.

No statistical differences were found between males and females for the self-efficacy domain $(t=1.69$; $p=0.09)$ and the task values domain scores $(t=0.60 ; p=0.55)$.

Females were less anxious about exams than males due to better motivation and higher involvements in learning activities than male students. This result is also consistent with many results that showed females' achievement was higher than that of males (Abdelhamid, 1999). Females were also better in self-regulation strategy than males, which is consistent with previous findings. Females normally employ better strategies for learning than male students and they tend to take the learning processes more serious than males often do.

In regard to the differences in motivated learning strategies between different academic steams, means, standard deviations, and $t$-values were calculated, as shown in Table 4.

Results of Table 4 showed a significant difference between science and arts academic streams on all four domains of the motivated learning strategies $(t=2.63,2.31,2.16$, and 2.58 in order; $p=0.009,0.021,0.032$, and 0.010 in order). Examining the mean values for each domain, it appeared that these significant differences were in favor of the science stream. 
These results indicate that science stream students take their learning processes more seriously and they seem to be less anxious because they use practical methods of studying. Furner et al. (2005) showed that scientific majors have higher expectations, internal control, and attribution, and have better beliefs of their abilities.

Table 4

Means, Standard Deviations, and T-Values for the Motivated Learning Strategies Domains Based on Academic Stream

\begin{tabular}{|c|c|c|c|c|c|c|}
\hline Domain & Academic stream & Freq. & Mean & $S D$ & $t$ & $p$ \\
\hline \multirow{2}{*}{ Self-efficacy } & Science & 468 & 3.11 & 0.84 & \multirow{2}{*}{2.63} & \multirow{2}{*}{0.009} \\
\hline & Arts & 302 & 2.95 & 0.86 & & \\
\hline \multirow{2}{*}{ Task values } & Science & 468 & 3.41 & 0.76 & \multirow{2}{*}{2.31} & \multirow{2}{*}{0.021} \\
\hline & Arts & 302 & 3.28 & 0.76 & & \\
\hline \multirow{2}{*}{ Test anxiety } & Science & 470 & 3.13 & 0.59 & \multirow{2}{*}{2.16} & \multirow{2}{*}{0.032} \\
\hline & Arts & 302 & 3.23 & 0.68 & & \\
\hline \multirow{2}{*}{ Self-regulation } & Science & 470 & 2.86 & 0.76 & \multirow{2}{*}{2.58} & \multirow{2}{*}{0.010} \\
\hline & Arts & 320 & 2.71 & 0.82 & & \\
\hline
\end{tabular}

In regard to the differences in motivated learning strategies domains based on student's grade, one-way analysis of variance (ANOVA) was conducted, as shown in Table 5.

Table 5

One-Way ANOVA Results for the Effect of Grade on Motivated Learning Strategies Domains

\begin{tabular}{|c|c|c|c|c|c|c|}
\hline Domain & Source & $S S$ & $D f$ & $M S$ & $f$ & $p$ \\
\hline & Between groups & 1.70 & 2 & 0.852 & & \\
\hline \multirow[t]{3}{*}{ Self-efficacy } & Within groups & 555.51 & 766 & 0.72 & 1.18 & 0.31 \\
\hline & Total & $5,553.21$ & 768 & - & & \\
\hline & Between groups & 1.44 & 2 & 0.722 & & \\
\hline \multirow[t]{3}{*}{ Task values } & Within groups & 448.92 & 766 & 0.586 & 1.23 & 0.29 \\
\hline & Total & 450.38 & 768 & - & & \\
\hline & Between groups & 1.805 & 2 & 0.902 & & \\
\hline \multirow[t]{3}{*}{ Test anxiety } & Within groups & 299.97 & 766 & 0.391 & 2.31 & 0.10 \\
\hline & Total & 301.77 & 768 & - & & \\
\hline & Between groups & 2.93 & 2 & 1.47 & & \\
\hline \multirow[t]{2}{*}{ Self-regulation } & Within groups & 469.74 & 766 & 0.61 & 2.39 & 0.09 \\
\hline & Total & 472.68 & 768 & - & & \\
\hline
\end{tabular}

Results of Table 5 showed that there were statistically significant differences in domains of motivated learning strategies based on grade of students $(f=1.18,1.23,2.31$, and $2.39 ; p=0.31,0.29,0.10$, and 0.09 in order). These results show that students' motivated strategies for learning are constant across grades of students (10th, 11th, and 12th) and suggest that more training is needed on such strategies during high school stage.

To answer the third question "What are the cognitive styles used by UAE high school students?", means, standard deviation, and rank of cognitive styles among UAE students were calculated, as shown in Table 6 . 
Table 6

Means, Standard Deviations, Level, and Rank for the Cognitive Styles Scores

\begin{tabular}{lllll}
\hline Domain & Mean & $S D$ & Level & Rank \\
\hline Field-independent & 3.97 & 0.55 & High & 1 \\
Field-dependent & 2.66 & 0.61 & Average & 2 \\
\hline
\end{tabular}

Based on the statistical norm used on the results of question one, results of Table 6 showed that students ranked high on the field-independent domain with a mean of 3.97 and ranked average in the field-dependent domain with a mean of 2.66 .

The previous findings showed that UAE students have a tendency to be more field-independent than filed-dependent. Filed-independent students seem to work well with others and like to participate in group discussion. This result is consistent with Witkin et al. (1977), who stated that field-independent learners tend to rely on information provided by the outer world since UAE students are more open to internationalization values and open systems of learning than most countries in the Middle-East. This result is also consistent with the results of Paul et al. (1994), who found the UAE students to prefer styles that deal with issues of physical or applied nature rather that abstract nature. However, these findings are not consistent with those of Altun and Cakan (2006), which indicated that more than a half of the participants were field-dependent and $36.9 \%$ of the participants were field-independent.

To answer the fourth question "Are there statistical differences in cognitive styles due to variation in student's gender, academic stream, and grades?", means, standard deviations, and $t$-values for the cognitive styles domains based on gender were calculated, as shown in Table 7.

Table 7

Means, Standard Deviations, and T-Values for the Cognitive Styles Domains Based on Gender

\begin{tabular}{lllllll}
\hline Domain & Gender & Freq. & Mean & $S D$ & $t$ & $p$ \\
\hline \multirow{2}{*}{ Field-independent } & Male & 322 & 3.82 & 0.58 & \multirow{2}{*}{7.66} & 0.001 \\
& Female & 471 & 4.12 & 0.53 & & \multirow{2}{*}{0.001} \\
\hline \multirow{2}{*}{ Field-dependent } & Male & 322 & 2.80 & 0.61 & \multirow{2}{*}{6.00} & 0.62 \\
& Female & 471 & 2.54 & & \\
\hline
\end{tabular}

Results in Table 7 showed statistically significant differences $(t=7.65 ; p=0.001)$ between males and females in scores of the field-independent in favor of females. Also, a statistically significant difference $(t=$ $6.00 ; p=0.001$ ) was found for the field-dependent in favor of males.

Results above clearly showed that female students are more field-independent and less filed-dependent than male students. Females are well known for their tendency to be independent of the field and ability to work with groups and go through extended discussions. Also, female students have more tendency to rely less on the teacher in the classroom and rely on themselves more than male students (Cassidy, 2004).

In regard to the differences in cognitive styles between different academic streams, means, standard deviations, and $t$-values were calculated, as shown in Table 8.

Results of Table 8 showed significant differences in field-independent cognitive styles based on students' stream $(t=4.21 ; p=0.001)$ in favor of science major students, and in field-dependent cognitive style based on students' stream $(t=4.66 ; p=0.001)$ in favor of arts major students. 
Table 8

Means, Standard Deviations, and T-Values for the Cognitive Styles Based on Academic Stream

\begin{tabular}{lllllll}
\hline Domain & Academic stream & Freq. & Mean & $S D$ & $t$ & $p$ \\
\hline \multirow{2}{*}{ Field-independent } & Science & 470 & 4.08 & 0.52 & \multirow{2}{*}{4.21} & 0.001 \\
& Arts & 300 & 3.90 & 0.61 & & \multirow{2}{*}{0.001} \\
\hline \multirow{2}{*}{ Field-dependent } & Science & 470 & 2.55 & 0.60 & 0.66 & \\
& Arts & 300 & 2.77 & 0.65 & & \\
\hline
\end{tabular}

The finding in the field-independent cognitive style is consistent with scientific stream students' characteristics, which they are known for their dedication, self-dependent, attend tasks on time, and enjoy their efforts on various tasks more than arts stream students. Also, arts students were better at field-dependent cognitive style since they are well known for their dependence on teachers and classmates, work individually, and use their thinking skills on solving art issues.

In regard to the differences in cognitive styles between different grade level students, one-way ANOVA was conducted, as shown in Table 9.

Table 9

One-Way ANOVA Results for the Effect of Grade on Cognitive Styles

\begin{tabular}{llrrrrl}
\hline Domain & Source & \multicolumn{1}{c}{$S S$} & \multicolumn{1}{c}{ D } & MS & $f$ & $p$ \\
\hline \multirow{4}{*}{ Field-independent } & Between groups & 2.06 & 2 & 1.03 & & 0.040 \\
& Within groups & 243.48 & 766 & 0.38 & 3.24 & 0.007 \\
& Total & 245.54 & 768 & - & & \\
\hline \multirow{3}{*}{ Field-dependent } & Between groups & 3.90 & 2 & 1.95 & & \\
& Within groups & 299.20 & 766 & 0.39 & -99 & \\
& Total & 303.10 & 768 & - & & \\
\hline
\end{tabular}

Results of Table 9 showed that there was a statistically significant difference in field-independent cognitive style based on student's grade $(f=3.24 ; p=0.040)$, and a statistically difference in field-dependent cognitive style based on student's grade $(f=4.99 ; p=0.007)$.

Post-hoc comparisons were calculated to determine the direction of statistical differences based on student's grade. In the field-independent style, a significant difference $(p=0.05)$ was found between 10th grade students and the 12th grade students in favor of the 10th grade. Also, in the field-dependent style, a significant difference $(p=0.05)$ was found between 10th and 11th grade students in favor of the 11th grade.

The previous difference resulted in field-dependent is consistent with previous research since they are more mature, however, the difference in the field-independent cognitive style is not consistent with the previous literature where the 12th grade students are expected to be better than 10th grade students. This could be explained in light of the pressure students face during their last year toward graduation and ministry final examination that usually causes a lot of stress and social pressure (Bagana, Racu, \& Lupu, 2011).

\section{Conclusion}

Based on the previous results that UAE students possess a moderate level of motivated learning strategies, we conclude that students must be trained on such learning strategies through different means of learning processes in the classrooms, specially strategies, such as self-regulation which is considered one of the 
meta-cognitive skills that required extensive training since early stages of schools. These strategies cannot be developed without changes to the curricula and class activities. Also, more attention should be given to students in the arts stream majors since they were lower in motivated learning strategies in general.

Results of the cognitive styles revealed a high level of field-independent style among students in general. However, males and arts stream students did not do as well in field-independent compared to females and science majors which suggests more attention to males and arts stream students to insure the development of independent cognitive styles. Differences between students in field-independent based on different classes were inconsistent since 10th grade students were better than 12th grade students which suggests other external values affecting the 12th grade students and further investigation.

\section{Recommendations}

Based on the above discussions and conclusions, the following recommendations could be made:

1. Conducting workshops for students in order to train them on motivated learning strategies;

2. Giving more attention to developing field-independent cognitive style for arts major students and males in general;

3. Investigating the inconsistent findings in field-independent between 10th and 12th grade students;

4. Conducting a study that links both the motivated learning strategies for learning and the cognitive styles to achievement for the UAE students;

5. Giving special attention to self-regulation motivated learning strategy through meta-cognitive training programs in schools.

\section{References}

Abdelhamid, A. (1999). The effect of motivation components and learning strategies on achievement and their relations to gender and grade. Journal of Education (Zagaziq University), 21(1), 11-18.

Abiator, A. (2001). Learning styles modalities. Retrieved from http://ww.berghuis.com.nz/Abiator/isismenu.html

Abu-Moghli, F. A., Khalaf, I. A., Halabi, J. O., \& Wardam, L. A. (2005). Jordanian baccalaureate nursing student's perception of their Learning styles. International Nursing Review, 52, 39-45.

Ahmad, I. (2005). Motivated learning strategies and its relation to intelligence, learning environment, and gender among high school students in Egypt. Journal of Education (Zagaziq University), 29(2), 12-24.

Altun, A., \& Cakan, M. (2006). Undergraduate students' academic achievement, field dependent/independent cognitive styles and attitude toward computers. Educational Technology \& Society, 9(1), 289-297.

Bagana, E., Racu, A., \& Lupu, L. (2011). Self-esteem, optimism and exams' anxiety among high school students. Procedia-Social and Behavioral Sciences, 30, 1331-1338.

Bolocofsky, D. (2014). Motivational effects of classroom competition as a function of field dependence. The Journal of Educational Research, 73(4), 213-217.

Cassidy, S. (2004). Learning styles: All overview of theories, models, and measures. Journal of Educational Psychology, 24(4), 419-444.

Daniels, H. L. (1996). Interaction of cognitive style and learner control of presentation mode in a hypermedia environment. Retrieved October 21, 2005, from http://scholar.lib.vt.edu/theses/available/etd- 3132141279612241/

Dunn, R., Dunn, K., \& Price, G. (1987). Learning style inventory (LS). Lawrence, K.S.: Price System.

Fang, N. (2014). Correlation between students' motivated strategies for learning and academic achievement in an engineering dynamics course. Journal of Engineering Education, 16(1), 25-32.

Furner, J., Yahya, W., \& Duffy, M. (2005). Teach mathematics: Strategies to reach all students. Intervention in School and Clinic, 41(1), 16-23.

Gibson, J. J. (1986). The ecological approach to visual perception. Hillsdale, N.J.: Erlbaum. (Original work published in 1979).

Gibson, J. J., \& Gibson, E. J. (1955). Perceptual learning: Differentiation or enrichment? Psychological Review, 62, 32-41. 
Hatcher, J. (2000). A casual comparative study: Motivational and learning strategies of development and no development freshman English composition students at Mississippi community colleges. DAI, 61(4), 1317A.

Johnson, G. (1991). Teaching tips for users of the motivated strategies for learning questionnaire. Michigan: EDRS.

Lawrence, G. (1987). People types and tiger stripes: A practical guide to learning styles (2nd ed.). Gainesville, F.L.: Center for Applications of Psychological Types.

Matos, L., Lens, W., \& Vansteenkiste, M. (2007). Achievement goals, learning strategies and language achievement among Peruvian high school students. Psychologica Belgica, 47(1), 51-70. Doi:http://dx.doi.org/10.5334/pb-47-1-51

Pajares, F. (2001). Toward a positive psychology of academic motivation. Journal of Educational Research, 95(1), 27-35.

Paul, S., Bojanczyk, M., \& Lanphear, J. H. (1994). Learning preferences of medical students. Medical Education, $28,180-186$.

Pearson, E., \& Cary, A. (1995). Learner strategies and learner interviews. ELT Journal, 42(3), 173-178.

Rao, N., \& Sachs, J. (1999). Confirmatory factor analysis of the Chinese version of the motivated strategies for learning questionnaire. Educational and Psychological Measurement, 59, 1016-1029.

Shih, C., \& Gamon, J. (2001). Web based learning: Relationships among students motivation, attitudes, learning styles, and achievement. Journal of Agricultural Education, 42(4), 12-20.

Usava, G., \& Gibson, M. (1986). Motivational strategies for curriculum development. Virginia: EDRS.

Witkin, H., Moore, C., Goodenough, D., \& Cox, P. (1977). Field-dependent and field-independent cognitive styles and their educational implications. Review of Educational Research, 47(1), 1-64.

Woolhouse, M., \& Blaire, T. (2003). Learning styles and retention and achievement on a two-year A-level programme in a further education college. Journal of Further and Higher Education, 27(3), 257-269. 